\title{
Specifically activated memory $T$ cell subsets from cancer patients recognize and reject xenotransplanted autologous tumors
}

\author{
Philipp Beckhove, ${ }^{1}$ Markus Feuerer, ${ }^{1}$ Mathias Dolenc,, ${ }^{1}$ Florian Schuetz, ${ }^{2}$ Carmen Choi, ${ }^{1}$ \\ Nora Sommerfeldt, ${ }^{1}$ Jochen Schwendemann, ${ }^{1}$ Katrin Ehlert, ${ }^{1}$ Peter Altevogt, ${ }^{1}$ Gunther Bastert, ${ }^{2}$ \\ Volker Schirrmacher, ${ }^{1}$ and Viktor Umansky ${ }^{1}$ \\ ${ }^{1}$ Division of Cellular Immunology, Tumor Immunology Program, German Cancer Research Center, Heidelberg, Germany. \\ ${ }^{2}$ Department of Obstetrics and Gynecology, University Hospital, Heidelberg, Germany.
}

\begin{abstract}
Bone marrow of breast cancer patients was found to contain $\mathrm{CD8}^{+} \mathrm{T}$ cells specific for peptides derived from breast cancer-associated proteins MUC1 and Her-2/neu. Most of these cells had a central or effector memory phenotype (CD45RA-CD62 $\mathrm{L}^{+}$or CD45RA-CD62- $\mathrm{L}^{-}$, respectively). To test their in vivo function, we separated bone marrow-derived CD45RA ${ }^{+}$naive or $\mathrm{CD} 45 \mathrm{RA}-\mathrm{CD}^{-} 5 \mathrm{RO}^{+}$memory $\mathrm{T}$ cells, stimulated them with autologous dendritic cells pulsed with tumor lysate, and transferred them into NOD/SCID mice bearing autologous breast tumors and normal skin transplants. CD45RA- memory but not $\mathrm{CD}^{-} 5 \mathrm{RA}^{+}$naive $\mathrm{T}$ cells infiltrated autologous tumor but not skin tissues after the transfer. These tumor-infiltrating cells had a central or effector memory phenotype and produced perforin. Many of them expressed the P-selectin glycoprotein ligand 1 and were found around P-selectin ${ }^{+}$tumor endothelium. Tumor infiltration included cluster formation in tumor tissue by memory $T$ cells with cotransferred dendritic cells. It was associated with the induction of tumor cell apoptosis and significant tumor reduction. We thus demonstrate selective homing of memory $T$ cells to human tumors and suggest that tumor rejection is based on the recognition of tumor-associated antigens on tumor cells and dendritic cells by autologous specifically activated central and effector memory $T$ cells.
\end{abstract}

\section{Introduction}

Recognition of tumor antigens (TAs) processed and presented by professional antigen-presenting cells (APCs) to naive CD45RA+ T cells leads to clonal expansion and to the generation of effector and memory CD45R0 $0^{+} \mathrm{T}$ cells. Thus, the frequency of $\mathrm{T}$ cells specific for TAs is much higher among memory than among naive $\mathrm{T}$ cells. Memory cells have several functional properties that distinguish them from naive cells, such as (a) an ability to respond to lower antigen concentrations, (b) faster proliferation following antigenic stimulation, (c) more rapid display of effector functions, (d) the potential to release a broader spectrum of cytokine, and (e) a pattern of adhesion molecules that allows access to peripheral tissues (1-3). Moreover, memory $\mathrm{T}$ cells are less dependent on costimulation provided by APCs (4-6) and can divide in the periphery long after antigen stimulation, sometimes even without any evidence for the persistence of their cognate antigen $(2,3)$.

The memory $\mathrm{T}$ cell population differs from naive $\mathrm{T}$ lymphocytes in the expression of several surface markers such as CD45 isoforms, $\beta$-integrins, CD44, CD62L (L-selectin), and CCR7 $(1,2,7)$. In many different species, the low-molecular-weight isoforms of CD45 are present on memory cells, whereas naive $\mathrm{T}$ cells express the highest-molecular-weight isoform (defined in

Nonstandard abbreviations used: adoptive cellular immunotherapy (ADI); antigenpresenting cell (APC); bone marrow (BM); central memory (CM); effector memory (EM); National Institute of Allergy and Infectious Diseases (NIAID); PBMC lysate (PB-L); peripheral blood (PB); phycoerythrin (PE); propidium iodide (PI); P-selectin glycoprotein ligand 1 (PSGL1); T cell receptor (TCR); tumor antigen (TA); tumor-infiltrating lymphocyte (TIL); tumor lysate (Tu-L).

Conflict of interest: The authors have declared that no conflict of interest exists.

Citation for this article: J. Clin. Invest. 114:67-76 (2004)

doi:10.1172/JCI200420278. humans as CD45R0 and CD45RA, respectively) (7). CD45RA ${ }^{+}$ naive $\mathrm{T}$ cells uniformly display high levels of CD62L and of the chemokine receptor CCR7. CD62L and CCR7 are required for cell entry into lymph nodes through high endothelial venules $(8,9)$. In contrast, a subpopulation of CD $45 \mathrm{R}^{+} \mathrm{CD}^{+} 5 \mathrm{RA}^{-}$memory $\mathrm{T}$ cells loses expression of these adhesion molecules. Instead, they express P-selectin glycoprotein ligand 1 (PSGL1), a ligand that mediates homing to P-selectin on peripheral tissues with activated inflamed endothelium (10). CD45R $0^{+} \mathrm{CD}_{4} 4 \mathrm{RA}^{-}$memory $\mathrm{T}$ cells can be divided into $\mathrm{CD} 62 \mathrm{~L}^{+} \mathrm{CCR} 7^{+}$nonpolarized 'central memory' (CM) and CD62 $\mathrm{L}^{-} \mathrm{CCR} 7^{-}$polarized 'effector memory' (EM) cell populations (11-15). These two subsets depend on different environmental and survival stimuli that determine their homing and functional properties $(12,13)$.

We previously reported that tumor cell-vaccinated mice harbor in their bone marrow (BM) small numbers of dormant tumor cells and also memory $\mathrm{T}$ cells that provide protection against further tumor cell challenge $(16,17)$. The BM of breast cancer patients was enriched for tumor-specific memory T lymphocytes (18). Such T cells could be stimulated in vitro to produce IFN- $\gamma$ and to acquire antitumor cytotoxicity in vitro and in vivo (19).

Pre-existing tumor-specific $\mathrm{T}$ cells from cancer patients apparently fail to reject tumors. It is believed that such failure is due to insufficient stimulation during priming, inadequate polarization of $\mathrm{T}$ cells with cytokines released by the tumor stroma, anergy, or direct immunosuppression within the tumor tissue (20). Therefore, vaccination protocols are designed to generate effector $T$ cells from naive cells $(21,22)$. However, the efficiency of such priming may be limited due to the low frequencies of tumor-specific naive $\mathrm{T}$ cells. In contrast, tumor-reactive memory $\mathrm{T}$ cells, which show higher frequency and are present in the BM of cancer patients, may 
exert therapeutic effects after reactivation and mobilization with appropriate tumor vaccines.

In the present study, we separated naive and memory $\mathrm{T}$ cells from $\mathrm{BM}$ of cancer patients, co-incubated them with TA-presenting DCs, and tested their potential to infiltrate and reject autologous tumor xenotransplants upon adoptive transfer with DCs. We demonstrate that only memory $\mathrm{T}$ cell subsets were capable of tumor infiltration and rejection. Tumor infiltration was associated with expression of PSGL1 on T cells and their colocalization with P-selectin ${ }^{+}$tumor endothelium, thus suggesting a role for these adhesion molecules in the homing of memory $\mathrm{T}$ cells to human breast cancer. Our results demonstrate that TA-specific activated $\mathrm{CM}$ and EM but not naive T cells from the BM of cancer patients have the therapeutically relevant property to selectively home to, recognize, and reject autologous tumor tissue.

\section{Results}

$T$ cell subsets in the BM of cancer patients. Mononuclear cells were freshly isolated from BM of 22 breast cancer patients and were stained for different $\mathrm{T}$ cell markers (Table 1 ). All $\mathrm{CD}^{+} \mathrm{T}$ cells expressed ICAM-3, which plays a key role in bidirectional interactions of T cells and DCs (23). Of BM T cells, $47 \%$ showed a naive phenotype $\left(\mathrm{CD} 45 \mathrm{RA}^{+} \mathrm{CD} 62 \mathrm{~L}^{+}\right.$) and $38 \%$, a memory phenotype $\left(\mathrm{CD}^{2} \mathrm{R} 0^{+} \mathrm{CD}^{2} 5 \mathrm{RA}^{-}\right)$. The latter subpopulation contained significantly more EM (CD45RA-CD62L-) than CM (CD45RA-CD62 $\left.\mathrm{L}^{+}\right)$ T cells $(25 \%$ and $13 \%$, respectively; $P<0.001)$. Most of CD62 $\mathrm{L}^{+}$cells within CD45RA ${ }^{-} \mathrm{T}$ cells simultaneously expressed CCR7, thereby suggesting their CM nature (Table 1 ). The P-selectin ligand PSGL1, which is expressed on a subset of memory T cells $(24,25)$, was detected on $76 \% \pm 12 \%$ of memory $T$ cells (Table 1 ). No significant differences in PSGL1 expression were found between CD4 ${ }^{+}$ and $\mathrm{CD}^{+} \mathrm{T}$ cells or between CM and EM T cells (data not shown). This shows the binding capacity for P-selectin of the majority of CD45R $0^{+} \mathrm{T}$ cells from both memory subsets.

TA-specific $C D 8^{+} T$ cell subsets from patients' $B M$. We determined the frequencies of $\mathrm{CD}^{+} \mathrm{T}$ lymphocytes from $\mathrm{BM}$ and peripheral blood (PB) of breast cancer patients and healthy donors with specificity for defined TAs by staining with tetrameric complexes containing HLA-A2 and peptides derived from the tumor-specific proteins MUC1 (LLLLTVLTV) or Her-2/neu (KIFGSLAFL) (Figure 1, A-C). Compared with staining with tetrameric complexes containing the HIV-derived peptide SLYNTVATL as a negative control, we detected low frequencies of MUC1- or Her-2/neu-specific T cells in $\mathrm{BM}\left(0.13 \% \pm 0.09 \%\right.$ and $0.15 \% \pm 0.10 \%$ of total $\mathrm{CD}^{+} \mathrm{T}$ cells; $n=7$ and 5 , respectively) and $\mathrm{PB}(0.10 \% \pm 0.08 \%$ and $0.14 \% \pm 0.08 \%$ of total $\mathrm{CD}^{+} \mathrm{T}$ cells; $n=15$ and 4 , respectively) of healthy donors. In contrast, patients had higher frequencies of TA-specific T cells in their BM $\left(0.37 \% \pm 0.8 \%\right.$ and $0.3 \% \pm 0.2 \%$ of total $\mathrm{CD}^{+} \mathrm{T}$ cells; $n=21$ and 15 , respectively) or $\mathrm{PB}(0.71 \% \pm 1.09 \%$ and $0.14 \pm 0.12 \%$ of total CD8 ${ }^{+} \mathrm{T}$ cells; $n=18$ and 8 , respectively) (Fig. 1, B and C). To define the $\mathrm{T}$ cell subsets with TA specificity, we also stained these samples with mAb's against CD8, CD45RA, and CD62L. Because we previously reported higher antitumor reactivity for BM T cells than for PB T cells (19), we focused this analysis on BM T cells. Among patients' $\mathrm{CD}^{+} \mathrm{T}$ cells there were significantly more TA-specific cells in the CD45RA- memory subset than among naive CD45RA ${ }^{+} \mathrm{T}$ cells $(70 \% \pm 26 \%$ versus $9 \% \pm 9 \%$, respectively, for MUC1 peptide, $n=7$; and $64 \% \pm 23 \%$ versus $17 \% \pm 14 \%$, respec-

Table 1

Phenotype analysis of freshly isolated BM T cells from breast cancer patients

\begin{tabular}{|c|c|c|c|c|c|c|c|c|}
\hline \multirow{2}{*}{$\begin{array}{l}\text { Patient } \\
\text { numbers }\end{array}$} & \multicolumn{6}{|c|}{$\%$ of CD3 T cells } & \multicolumn{2}{|c|}{$\%$ of CD45RA- T cells } \\
\hline & CD45RA+CD62L+ & CD45RA+CD62L- & CD45RA- $^{-}$ & CD45RA-CD62L+ & CD45RA-CD62L- & ICAM3+ & CD62L+CCR7+ & PSGL1+ \\
\hline 1 & 34 & 34 & 32 & 21 & 11 & N.D. & 90 & 85 \\
\hline 2 & 24 & 8 & 68 & 25 & 43 & N.D. & 94 & 68 \\
\hline 3 & 52 & 7 & 41 & 10 & 31 & N.D. & 85 & 71 \\
\hline 4 & 17 & 28 & 55 & 22 & 33 & N.D. & N.D. & 60 \\
\hline 5 & 46 & 11 & 43 & 11 & 32 & N.D. & 85 & 67 \\
\hline 6 & 76 & 5 & 19 & 3 & 16 & N.D. & N.D. & N.D. \\
\hline 7 & 40 & 17 & 43 & 13 & 30 & N.D. & 60 & N.D. \\
\hline 8 & 61 & 12 & 27 & 9 & 18 & N.D. & 70 & N.D. \\
\hline 9 & 39 & 23 & 38 & 13 & 25 & N.D. & N.D. & N.D. \\
\hline 10 & 65 & 7 & 28 & 6 & 22 & N.D. & 90 & N.D. \\
\hline 11 & 78 & 3 & 19 & 3 & 16 & N.D. & N.D. & N.D. \\
\hline 12 & 49 & 26 & 25 & 7 & 18 & N.D. & 95 & N.D. \\
\hline 13 & 25 & 12 & 63 & 23 & 40 & N.D. & N.D. & N.D. \\
\hline 14 & 50 & 10 & 40 & 10 & 30 & N.D. & N.D. & 83 \\
\hline 15 & N.D. & N.D. & N.D. & N.D. & N.D. & N.D. & N.D. & 70 \\
\hline 16 & N.D. & N.D. & N.D. & N.D. & N.D. & N.D. & N.D. & 60 \\
\hline 17 & N.D. & N.D. & N.D. & N.D. & N.D. & 100 & N.D. & 96 \\
\hline 18 & N.D. & N.D. & N.D. & N.D. & N.D. & 100 & N.D. & 98 \\
\hline 19 & N.D. & N.D. & N.D. & N.D. & N.D. & 100 & N.D. & 76 \\
\hline 20 & N.D. & N.D. & N.D. & N.D. & N.D. & 100 & N.D. & N.D. \\
\hline 21 & N.D. & N.D. & N.D. & N.D. & N.D. & 100 & N.D. & N.D. \\
\hline 22 & N.D. & N.D. & N.D. & N.D. & N.D. & 100 & N.D. & N.D. \\
\hline Mean \pm SD & $47 \pm 18$ & $15 \pm 9$ & $38 \pm 15$ & $13 \pm 7$ & $25 \pm 9$ & $100 \pm 0$ & $84 \pm 12$ & $76 \pm 13$ \\
\hline
\end{tabular}



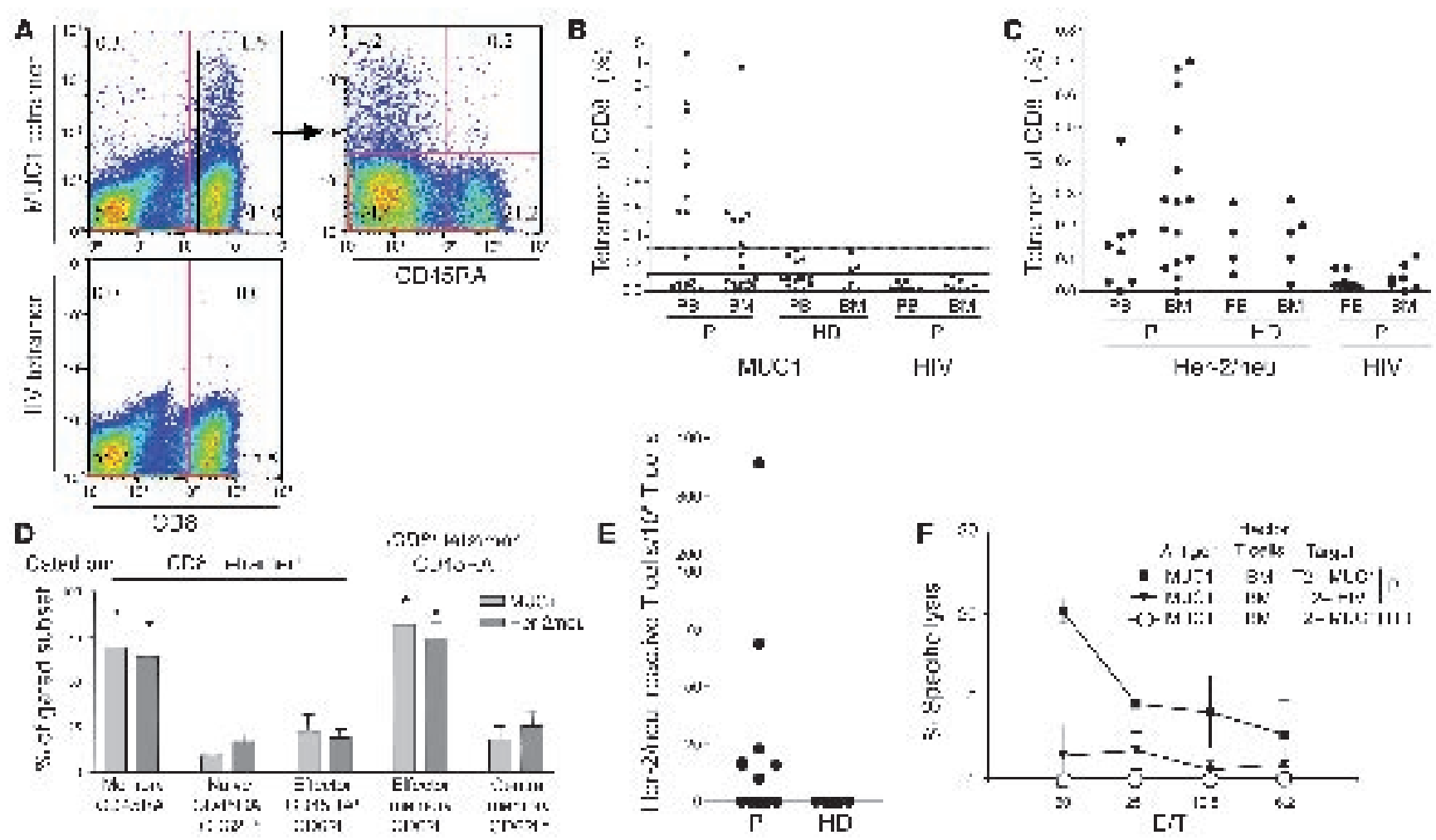

Figure 1

TA specificity and function of BM memory $T$ cells from breast cancer patients. (A) T cells were stained with tetramers containing HLA-A2 and the MUC1 peptide LLLLTVLTV or the irrelevant HIV peptide SLYNTVATL. Representative data are shown. Blue, low density of cells; yellow, high density of cells. (B and $\mathbf{C}$ ) Frequencies of MUC1- or Her-2/neu-specific CD8 ${ }^{+} T$ cells from BM and PB of patients (P) and healthy donors (HD). Maximal levels of tetramer-binding CD8 ${ }^{+} \mathrm{T}$ cells from healthy donors are depicted by dotted lines. Frequencies of $\mathrm{HIV}$-specific CD8 ${ }^{+} \mathrm{T}$ cells from $\mathrm{BM}$ and PB of nine breast cancer patients are shown. Maximum levels of nonspecific bindings are depicted by solid lines. (D) Accumulative data for MUC1- and Her-2/neu-binding CD8 ${ }^{+} T$ cells expressing memory markers (seven and six patients, respectively). ${ }^{*} P<0.0001$, memory versus naive cells; ${ }^{*} P<0.0001$, EM versus CM cells. (E) Frequencies of Her-2/neu-specific BM T cells from patients or healthy donors, measured by IFN- $\gamma$ ELISPOT after stimulation by DCs pulsed with the Her-2/neu peptide KIFGSLAFL. (F) MUC1-specific cytotoxicity of BM T cells. Patient (filled squares and filled triangles) or donor (open circles) cells were stimulated for 5 days with DCs pulsed with the MUC1 peptide LLLLTVLTV. HLA-A2 ${ }^{+}$T2 target cells were loaded with LLLLTVLTV (filled squares, open circles) or SLYNTVATL (filled triangles) peptides. X axis represents effector/target $(E / T)$ ratios.

tively, for Her-2/neu peptide, $n=8 ; P<0.0001$; Figure 1D). Within the memory population, TA-specific T cells had an EM rather than a CM phenotype $(81 \% \pm 17 \%$ versus $19 \% \pm 17 \%$, respectively, for MUC1 peptide; and $74 \% \pm 18 \%$ versus $26 \% \pm 18 \%$, respectively, for Her-2/neu peptide; $P<0.0001$, Figure 1D).

After short-term incubation with autologous DCs pulsed with the Her-2/neu-derived peptide KIFGSLAFL, BM memory T cells from 7 of 26 tested patients were able to produce IFN- $\gamma$ by ELISPOT assay (Figure 1E). In contrast, none of seven healthy donors contained Her-2/neu-reactive T cells in their BM. Furthermore, specifically activated $\mathrm{T}$ cells from all five patients tested produced perforin (data not shown) and exerted specific cytotoxicity against HLA-A2 ${ }^{+}$T2 target cells loaded with MUC1-derived peptide, while $\mathrm{BM} \mathrm{T}$ cells from four tested HLA-matched healthy donors stimulated in a similar way failed to exert TA-specific cytotoxicity (Figure $1 \mathrm{~F}$ ). In addition, the $\mathrm{BM}$ of all these patients contained significantly higher numbers of $\mathrm{CD}^{+} \mathrm{T}$ cells binding to HLA-A2/MUC1 tetramers (>0.3\% of total $\mathrm{CD}^{+} \mathrm{T}$ cells) than did BM of healthy donors (data not shown). These results corroborate our previous study in which DCs loaded with tumor lysate reactivated memory $\mathrm{T}$ cells, which then developed into IFN- $\gamma$-producing and cytotoxic effector cells (19). Thus, TA-specific memory T cells from patients' $\mathrm{BM}$ are apparently primed by TAs from their own tumor and can recognize and react to TA cross-presented on DCs.

Selective homing to xenotransplanted tumor by autologous $C D 45 R 0^{+}$ $E M$ and $C M$ but not by CD45RA $A^{+} T$ cells. To test the therapeutic potential of different $T$ cell subsets from cancer patients, we designed a protocol of adoptive cellular immunotherapy (ADI) that is outlined in Figure 2. BM aspirates from a cancer patient provided the source of mononuclear cells for in vitro generation of autologous T cells and DCs, which were further depleted of contaminating cells as previously described (19). Then, T cells were separated via MACS MicroBeads into CD45RA naive and CD45RA- memory subsets. DCs were pulsed with autologous tumor lysate (Tu-L) or with autologous PBMC lysate (PB-L) (as a negative control; not depicted) followed by co-incubation for 20 hours with a fivefold excess of sorted memory or naive $\mathrm{T}$ cells. Finally, cell suspensions containing $2.5 \times 10^{6} \mathrm{~T}$ lymphocytes and $0.5 \times 10^{6} \mathrm{DCs}$ were inoculated intraperitoneally into NOD/SCID mice that had been implanted subcutaneously 16 days before with $5 \times 5-\mathrm{mm}$ pieces of autologous freshly excised primary tumors and of normal skin. Then, 9-21 days later, the 


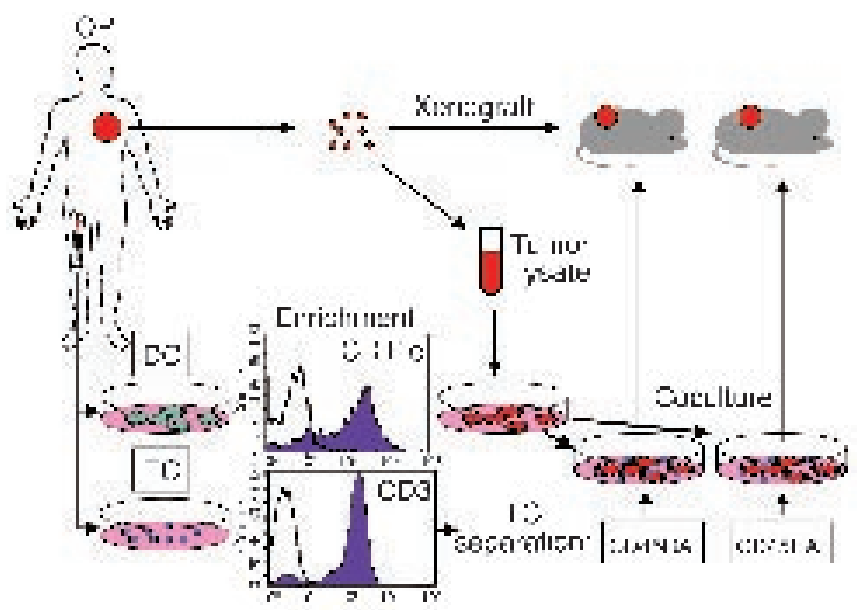

Figure 2

Scheme of ADI with activated autologous memory or naive T cells of human breast cancer specimens transplanted into NOD/SCID mice. After surgery, breast cancer specimens were transplanted subcutaneously into NOD/SCID mice. BM aspirates were obtained from patients during surgery. DCs and T cells (TC) from patients' BM were generated, pulsed and transferred into NOD/SCID mice as described in Methods. Representative histograms show stainings for corresponding markers on enriched cell subsets (purple) and for isotype control (white). OP, tumor excision.

experiment was terminated and human tumor and skin tissue were removed and analyzed for infiltrating cells.

After adoptive transfer, the separated and specifically stimulated

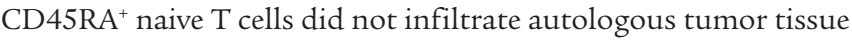
(Figure $3 \mathrm{~A}$ and Table 2 ). In contrast, the separated and specifically stimulated memory $\mathrm{T}$ cells were found to infiltrate autologous human tumor transplants. Interestingly, the cells did not infiltrate autologous normal skin transplants (Figure 3A), which showed no signs of inflammation. Tumor-infiltrating lymphocytes (TILs) contained CD4 as well as CD8 T cells that expressed the memory marker CD45R0 and were CD45RA- (Figure 3B). Tumor infiltration was antigen specific, as $T$ cells activated with irrelevant antigens (PB-L instead of Tu-L) were only found in very low numbers within tumor tissue (Table 2). For in vivo experiments, we used for specific activation of BM T cells DCs pulsed with autologous Tu-L rather than with tumor-specific peptides, because Tu-L mimics a physiological situation and allows polyclonal activation of $\mathrm{CD}^{+}$ and $\mathrm{CD}^{+} \mathrm{T}$ cells. Memory $\mathrm{T}$ cells from breast cancer patients were able to distinguish DCs pulsed with autologous Tu-L from DCs pulsed with autologous PB-L, as they were activated only by the former APCs. CD62L staining of TILs revealed the presence of both CM and EM T cells (44\% and $56 \%$ of infiltrating $\mathrm{CD}^{+} \mathrm{T}$ cells, respectively), indicating that both subsets were able to enter peripheral nonlymphatic tumor tissue (Table 2). Nine days after the transfer, the $\mathrm{T}$ cell activation marker CD26 was expressed by some TILs ( $34 \% \pm 8 \%$ of total $\mathrm{CD}^{+} \mathrm{T}$ cells; $\left.n=5\right)$, whereas the early activation marker CD69 was not detected. Almost half of these TILs showed expression of CD62L $\left(40 \% \pm 9 \%\right.$ of CD3 ${ }^{+} \mathrm{T}$ cells; $n=5$ ), suggesting their CM phenotype. Immunohistochemical staining also revealed the presence of transferred CD $11 \mathrm{c}^{+} \mathrm{DCs}$ in the tumor (Figure $3 \mathrm{C}$ ), which were often seen in close association with $\mathrm{CD}^{+} \mathrm{T}$ cells (Figure $3 \mathrm{C}$ ). In contrast, transferred CD $11 \mathrm{c}^{+} \mathrm{DCs}$ were not found in skin transplants (Figure 3D).
Expression of P-selectin by inflamed peripheral endothelium plays a major role in directing memory and effector $\mathrm{T}$ cells to the sites of inflammation (10). We therefore investigated the role of this adhesion molecule in $\mathrm{T}$ cell trafficking to breast cancer. We found expression of P-selectin in nine of ten primary breast tumors (Figure 4A) but not in skin biopsies or their xenotransplanted counterparts (data not shown). P-selectin expression was retained for a long time after transplantation of these tumors into NOD/SCID mice in seven of nine cases (78\%) (Figure 4B). Moreover, at day 9 after the transfer of activated autologous BM memory $\mathrm{T}$ cells into tumor-bearing animals, we found PSGL1+ $\mathrm{T}$ cells in close proximity to P-selectin ${ }^{+}$endothelium (Figure 4, C and D). Therefore, interactions between PSGL1 and P-selectin could facilitate tumor tissue infiltration by transferred memory T cells. We did not detect PSGL1-expressing T cells in tumor grafts from control animals (which did not receive autologous memory $\mathrm{T}$ cells), most probably due to the emigration of pre-existing TILs (ref. 24 and data not shown).

The fact that adoptive transfer of CD45RA+ naive T cells did not lead to tumor infiltration could be related to their insufficient survival. To investigate this, we reisolated cells from spleen 30 days after transfer of $2.5 \times 10^{6}$ naive or $2.5 \times 10^{6}$ memory $\mathrm{T}$ cells. The spleens of mice that received naive $\mathrm{T}$ cells contained $0.04 \%$ human $\mathrm{CD}^{+} \mathrm{T}$ cells, while spleens of mice that received memory $\mathrm{T}$ cells contained $0.13 \%$ human $\mathrm{CD}^{+} \mathrm{T}$ cells. A majority of transferred

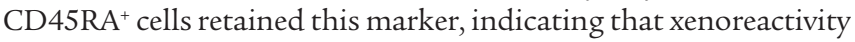
did not play a major role in $\mathrm{T}$ cell activation in this experimental setting. Animals receiving memory T cells harbored almost exclusively $\mathrm{T}$ cells of memory phenotype (data not shown). Thus, both naive and memory human $T$ cells survived for a long time after transfer into NOD/SCID mice.

Perforin expression and tumor regression by $C D 45 R 0^{+}$but not $C D 45 R A^{+}$ $T$ cells. Intracellular staining of BM T cells from seven breast cancer patients at day 6 of coculture with DCs pulsed with Tu-L revealed perforin expression in both $\mathrm{CM}$ and $\mathrm{EM} \mathrm{CD} 8^{+} \mathrm{T}$ cells (Figure 5, A and $B$ ). This suggests an acquisition of cytolytic capacity in both subsets within 1 week of stimulation. In contrast, the CD45RA ${ }^{+}$ naive fraction stimulated under the same conditions did not contain perforin-expressing cells (data not shown). A single injection of specifically re-stimulated autologous sorted CD45RA- memory BM T cells together with DCs into NOD/SCID mice at day 16 after tumor implantation resulted in a significant decrease in tumor diameter compared with that of either untreated animals or animals treated with nonspecifically re-stimulated memory $\mathrm{T}$

\section{Table 2}

Immunohistological analysis of tumor-infiltrating CD3+ T cells

\begin{tabular}{llrrrr} 
& & \multicolumn{2}{c}{ CD45RA- $^{-}$} & \multicolumn{2}{c}{ CD45RA $^{+}$} \\
& & \multicolumn{1}{c}{ Tu-L } & PB-L & Tu-L & PB-L \\
Day 9 & CD3 $/ \mathrm{mm}^{2}$ & $54 \pm 34$ & $5 \pm 4$ & $0.2 \pm 0.1$ & $0.2 \pm 0.1$ \\
Day 21 & CD3 $/ \mathrm{mm}^{2}$ & $112 \pm 23$ & $14 \pm 7$ & $0.3 \pm 0.2$ & $0.2 \pm 0.2$
\end{tabular}

NOD/SCID mice bearing human breast cancer specimens were treated with autologous CD45RA- memory or CD45RA+ naive T cells reactivated with DCs pulsed with Tu-L or PB-L. Mice were killed for analysis at day 9 or day 21 after therapy. Frozen tumor sections were stained with $m A b$ against human $C D 3$. Numbers represent means $\pm S D$ for $C D 3^{+} T$ cells $/ \mathrm{mm}^{2}$ of tumor tissue from three independent experiments (tissues from three patients were transplanted into five mice per group). Three sections from each tumor were analyzed. 


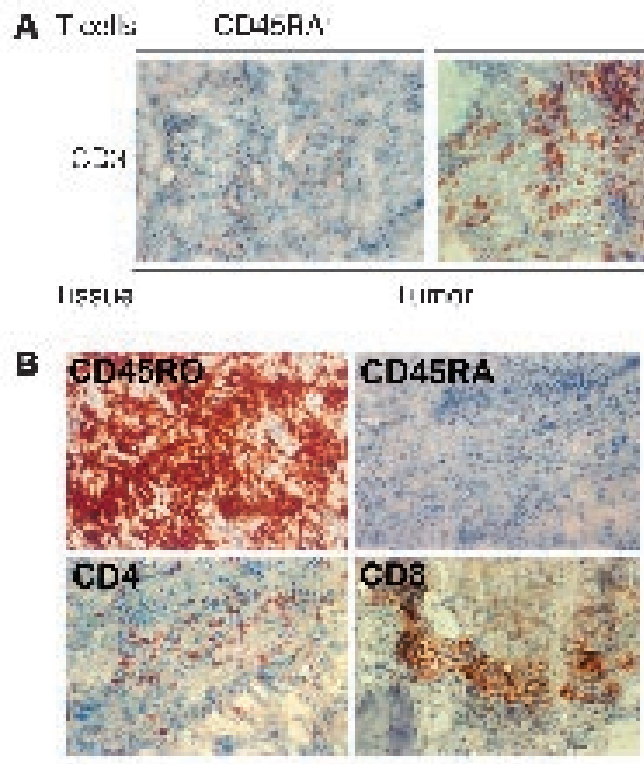

CDAFF
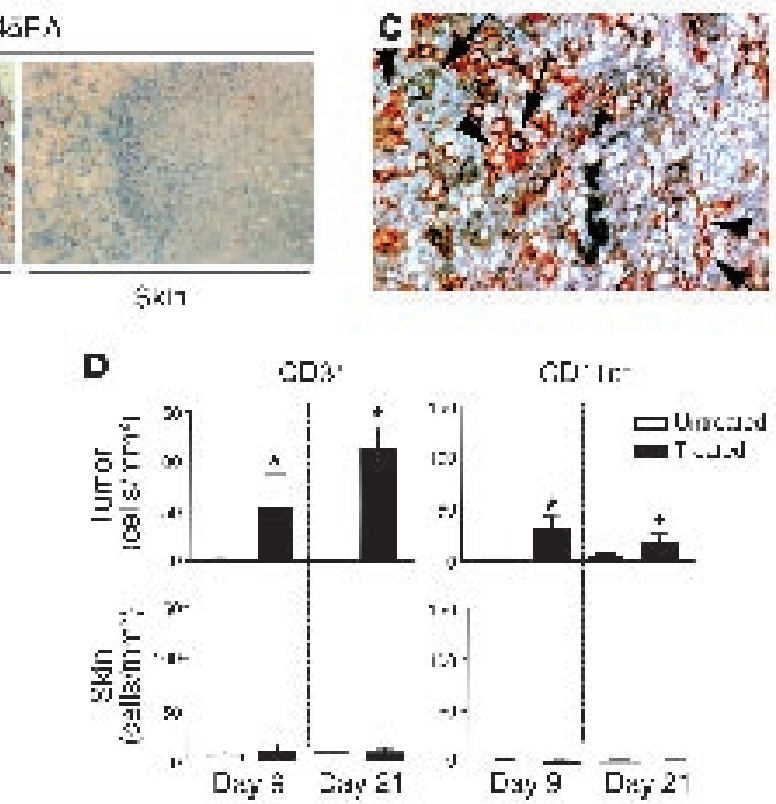

\section{Figure 3}

Characterization of tumor-infiltrating cells after ADI. Breast cancer or normal skin specimens from three patients were xenotransplanted into five mice. (A) Staining with mAb against CD3 21 days after transfer of autologous memory or naive T cells into tumor-bearing mice. (B) Phenotype of tumor-infiltrating memory T cells 21 days after their transfer into tumor-bearing mice. Tumor tissue was stained with mAb's against CD4, CD8, CD45R0, and CD45RA. Slides from A and B were counterstained with hemalaun. (C) Colocalization of transferred DCs (CD11c, dark blue; arrows) and T cells (red; arrowheads) within tumor tissue 21 days after adoptive transfer. Original magnifications, $\times 250$ (A and B) and $\times 400$ (C). (D) Numbers of CD3+ T cells and CD11 C $^{+}$DCs in tumor or skin transplants determined by immunohistochemistry at day 9 and day 21 after ADI (black bars) and from untreated mice (white bars). Tumor and skin transplants from untreated mice (white bars) were used as a control. Means \pm SD from three independent experiments (specimens from three patients transplanted into five mice) are depicted. Three sections per transplant and mouse were analyzed. ${ }^{*} P<0.05$, significant differences compared with corresponding untreated controls.

cells or compared with that of animals treated with specifically stimulated naive $\mathrm{T}$ cells from the same patient (Figure 5C). Tumor size reduction was associated with the presence of large numbers of perforin-expressing $\mathrm{T}$ cells around tumor lobules (Figure 5, D and $\mathrm{H}$ ) and with the emergence of multiple apoptotic cells within tumor lobules, most likely representing dead tumor cells (Figure $5, \mathrm{~F}$ and $\mathrm{H}$ ). In contrast, in tumors from untreated mice, we found no perforin-expressing cells (Figure 5, E and H) and only a few apoptotic cells (Figure 5, G and H).

\section{Discussion}

This study addresses the therapeutically important issue of tumor target recognition and infiltration by subsets of specifically reactivated autologous human T cells. As homing to a target tissue is a prerequisite for its rejection by $\mathrm{T}$ cells, the identification of the molecules and mechanisms of tissue-specific homing is important. The trafficking patterns of memory $\mathrm{T}$ cells are remarkably heterogeneous and distinct from those of naive $\mathrm{T}$

\section{Figure 4}

Colocalization of P-selectin-expressing xenotransplanted tumor endothelium and PSGL1+ T cells in ADI-treated animals. Tumor tissues from three patients were transplanted into five mice. (A and $\mathbf{B})$ P-selectin expression (red) in primary tumor $(\mathbf{A})$ and 19 days after xenotransplantation (B). Slides were counterstained with hemalaun. (C and D) P-selectin expression (red) and PSGL1 expression (dark blue; arrowheads) by human TILs 9 days after ADI. Original magnifications, $\times 200(\mathbf{A}$ and $\mathbf{B})$ and $\times 400(\mathbf{C}$ and $\mathbf{D})$. lymphocytes that home to secondary lymphoid tissues. Previous studies provided evidence that tumor- or pathogen-specific memory $\mathrm{T}$ cells are enriched in the BM of mice and humans (12, $16,18,26)$ and that tumor-specific memory $\mathrm{T}$ cells generated in the BM of cancer patients can exert antitumor effects after shortterm stimulation (19).

To study the migration of transferred, specifically reactivated, patient BM memory or naive $\mathrm{T}$ cells and their potential for tumor rejection, we applied the recently described NOD/SCID mouse model, which is suitable for the engraftment of human breast tumors and normal cells $(27,28)$. Autologous breast cancer trans-

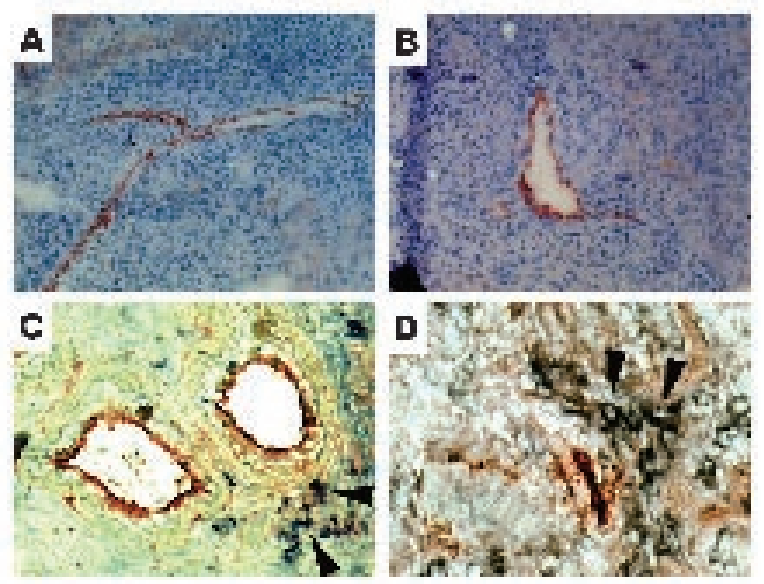


plants were shown to engraft in NOD/SCID mice without changing their histomorphology or expression of tumor markers (e.g., MUC1) $(19,29)$. Transfer of sorted, autologous, reactivated BM memory $\mathrm{T}$ cells $\left(\mathrm{CD}^{2} \mathrm{RA}^{-} \mathrm{CD} 45 \mathrm{R} 0^{+}\right)$and $\mathrm{DCs}$ led to an infiltration of tumor transplants in NOD/SCID mice by CD4 and CD8 T cells as well as DCs. DCs often colocalized with the T cells and were previously shown to play an important role in this ADI model (30). Infiltration with DCs and CD4 and CD8 T cells was associated with tumor regression and tumor cell destruction in situ, suggesting a possible role of each cell type in tumor regression (30-32). In contrast, enriched naive BM T cells $\left(\mathrm{CD} 45 \mathrm{RA}^{+}\right)$, after adoptive transfer, failed to migrate into the tumor area and to cause tumor regression. As no or few $\mathrm{T}$ lymphocytes or DCs were observed in patients' tumor specimens growing in control (untreated) mice or in mice treated with sorted re-stimulated naive T cells and DCs, almost all human tumor-infiltrating cells detected in tumor transplants from ADI-treated groups originated from the injected memory $T$ cells that were specifically reactivated by cognate interaction with TA-presenting DCs (30).

Numerous previous studies performed in SCID mice with human tumor cells demonstrated impaired effector functions or even anergy of allogeneic human $\mathrm{T}$ lymphocytes upon their adoptive transfer $(33,34)$. In view of those experiences, the strong graft-versus-tumor reactivity observed in this ADI model with autologous patient-derived $T$ cells appears particularly significant. It may be explained (a) by the proper compartment (i.e., BM) from which the T cells were derived $(18,19)$; (b) by the specific re-stimulation step ex vivo suitable for memory cell activation (19); (c) by the choice of the NOD/SCID mouse as a recipient (29); and (d) by the co-injection of T cells with TA-presenting DCs, thereby allowing cognate T cell-DC interactions via T cell receptor/TA (TCR/TA) (30) and ICAM-3/DC-SIGN (23) in situ.
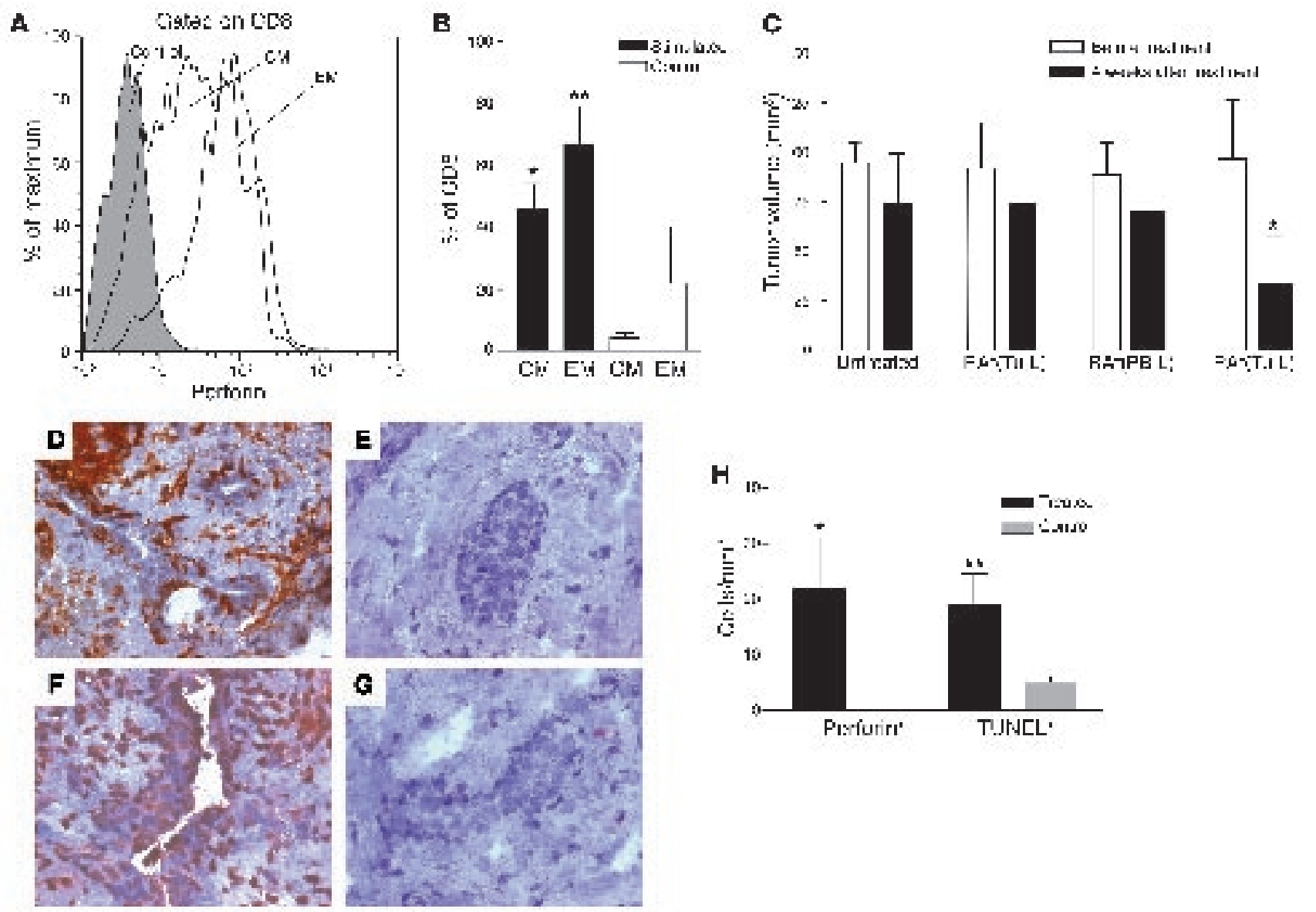

\section{Figure 5}

Perforin expression by autologous memory T cells and rejection of xenografted cancer specimens in NOD/SCID mice after ADI. (A) Perforin expression (with isotype control depicted in gray) in CD8 ${ }^{+}$CD45RA- CM and EM T cells 6 days after coculture with DCs pulsed with autologous Tu-L. Results from one representative experiment of four are shown. (B) Accumulative data for perforin expression by memory $T$ cells from BM of four patients stimulated with DCs pulsed with Tu-L (black bars) or left unstimulated (white bars). ${ }^{*} P<0.01 ;{ }^{* *} P<0.05$. (C) Tumor volumes were measured before therapy (white bars) and 4 weeks after therapy (black bars). Means \pm SD of three independent experiments. Mice were left untreated (control) or were injected with memory T cells activated by DCs pulsed with Tu-L [CD45RA-; RA-(Tu-L)] or PB-L [CD45RA-; RA-(PB-L)], or were treated with naive T cells activated by DCs pulsed with Tu-L [CD45RA+; RA+(Tu-L)]. * $P=0.03$ for the experimental (CD45RA-, TU-L) versus each control group. (D-G) Tumors from treated (D and $\mathbf{F})$ or untreated $(\mathbf{E}$ and $\mathbf{G})$ animals were stained for perforin $(\mathbf{D}$ and $\mathbf{E})$ and apoptotic cells $(\mathbf{F}$ and G) 9 days after therapy. Original magnification, $\times 200$. (D). Staining from one representative experiment of three is shown. (H) Accumulative data of perforin ${ }^{+}$and apoptotic cells in treated (black bars) and untreated (gray bars) tumors. ${ }^{*} P<0.01$, difference between numbers of perforin ${ }^{+}$TILs in experimental and control mice; ${ }^{* *} P<0.05$, difference between apoptotic cell numbers in experimental and control animals. 
This study characterized BM T cells from breast cancer patients with regard to phenotype, fine specificity and function to find out which cells were capable of human tumor infiltration. Patients' $\mathrm{BM}$ contained both $\mathrm{CM}$ and $\mathrm{EM} \mathrm{CD} 4^{+}$and $\mathrm{CD}^{+} \mathrm{T}$ cells. Tetramer staining revealed the presence of both $\mathrm{CM}$ and $\mathrm{EM} \mathrm{CD} 8^{+} \mathrm{T}$ cells specific for peptides derived from the breast cancer-associated proteins MUC1 and Her-2/neu $(35,36)$. CCR7-CD62L- EM cells recognizing a peptide of Melan-A have been demonstrated in melanoma patients (37). Furthermore, we found that memory cells produced IFN- $\gamma$ and became cytotoxic after re-stimulation with DCs loaded with peptides derived from Her-2/neu or MUC1 but not with irrelevant peptides (from insulin or HIV). In addition, none of the healthy donors tested had tumor-reactive T cells in their BM. These data indicate the specificity of the observed antitumor responses.

In the present study, BM-derived EM and CM T cells expressed perforin after being stimulated with DCs pulsed with Tu-L. The perforin/granzyme system is important for the cytotoxic activity of $\mathrm{CD} 8^{+} \mathrm{T}$ cells and can result in apoptosis of target tumor cells (38). Our findings suggest that both memory subsets derived from $\mathrm{BM}$ of cancer patients can be responsible for the observed therapeutic effects. CM T cells express CD62L and the chemokine receptor CCR7 and home to the $T$ cell areas of secondary lymphoid organs. In contrast, $\mathrm{CCR} 7^{-} \mathrm{CD} 62 \mathrm{~L}^{-}$EM cells acquire the capacity to migrate to nonlymphoid tissues (11-15). Although CM but not EM cells accumulated in lymph nodes, both cell types were detected in similar amounts in nonlymphoid tissues such as liver and lung (39). Therefore, CM and EM T cells may be flexible and capable of changing their homing properties.

The migration of effector and memory $T$ cells to inflamed tissues is mediated by P-selectin expressed on activated endothelium (10), whereas retaining of T cells in inflamed tissues depends on antigen recognition on infected or tumor cells (recognized by CD8 T cells) or on APCs (recognized by CD4 and CD8 T cells) (40). P-selectin was found to be expressed in a majority of human breast tumors (41). As P-selectin expression was conserved in most tumors after xenotransplantation into NOD/SCID mice, recognition of this receptor by the transferred tumor-specific memory $\mathrm{T}$ cells could provide a potential basis for their immigration. It has been shown that induction of PSGL1 on T cells requires both antigen-specific activation via the TCR and additional signals from DCs, such as IL-12 $(24,25)$. This cytokine plays a major role in the induction and maintenance of Th1 cells, which in contrast to Th2 cells express PSGL1 upon activation (25). We have recently demonstrated a release of high amounts of IL-12 by autologous DCs loaded with Tu-L from breast cancer patients upon cognate interaction in vitro with TA-reactive, IFN- $\gamma$-secreting Th1 T cells $(19,30)$. In accordance with this finding, we observed here that more than $30 \%$ of adoptively transferred memory $T$ cells infiltrating autologous tumors expressed PSGL1. Furthermore, both CM and EM T cells from patients expressed high levels of PSGL1. Accordingly, both subsets could be detected within xenotransplanted tumors after adoptive transfer. The data on CM T cell infiltration are supported by recent findings in a murine model describing efficient rejection of pathogens in nonlymphatic tissues by CM T cells (39).

We saw virtually no infiltration of implanted breast cancer tissue by $\mathrm{T}$ cells after transfer of stimulated CD45RA ${ }^{+}$naive T cells, although such cells survived in the PB and spleen of the xenogeneic host. The absence of tumor infiltration may reflect a low activation rate of these T cells by TA-pulsed DCs due to low numbers of TA- specific precursors, resulting in a consequent lack of PSGL1 induction. Blocking experiments have demonstrated an essential role for interactions between P-selectin and its ligands in the migration of murine memory and effector T cells to inflamed tissues (10). Memory T cells activated with TA-laden DCs migrated only into autologous tumor specimens but not into autologous normal tissue (skin transplants). Skin tissue, which was used as a control, differed from tumor tissue in tissue antigen expression and in the pattern of adhesion molecules expressed on its endothelia. It remains to be determined if the lack of skin infiltration was due to the absence of activated autoreactive $\mathrm{T}$ cells or to insufficient adhesion molecule expression. Yee et al. (21) have recently reported that a melanoma patient developed inflammatory vitiligo in the skin after adoptive transfer of activated MART-1/MelanA-specific $\mathrm{CD}^{+} \mathrm{T}$ cells, thus suggesting that these cells can invade not only tumor but also normal tissues. It is important, however, that activated memory $\mathrm{T}$ cells were able to distinguish between malignant and benign tissues. The selectivity was thus seen at the level of $\mathrm{T}$ cell subsets (CD45R0 ${ }^{+}$versus $\mathrm{CD}^{2} 5 \mathrm{RA}^{+}$cells) and at the level of the target (tumor versus normal) tissues.

We observed that both memory $\mathrm{T}$ cell types and DCs, which were involved in cognate interactions during the short-term ex vivo memory stimulation step, comigrated in vivo to the site of the tumor, where they formed clusters (Fig. 3C), and later on to the $\mathrm{BM}$ (our unpublished observation). DCs are known to deliver survival signals to $T$ cells especially during cognate interactions (42). We previously reported increased production of IFN- $\alpha$ and IL-15 (which may represent such survival factors) in the supernatants of T cell-DC cocultures upon cognate interaction $(30,43)$. IFN- $\alpha$ induced in DCs by human T cells was shown to be required for IL-12 receptor $\beta$ expression on human T cells, which then enabled them to respond to IL-12 and to differentiate into Th1 cells (44). IL-15 is produced by several cell types, including DCs, and plays an essential role in the expansion of human antigen-specific memory $\mathrm{CD}^{+}$and $\mathrm{CD}^{+} \mathrm{T}$ cell populations in vivo $(45,46)$. We have recently reported that ADI was not successful when the re-stimulated human BM T cells were transferred without DCs (30). The longterm survival of DCs in vivo might be explained by appropriate stimulatory signals obtained from activated $\mathrm{T}$ cells (47). Thus, the transfer of re-stimulated memory $\mathrm{T}$ cells and DCs may provide in vivo survival factors important for both cell types.

In conclusion, we have demonstrated that BM of breast cancer patients contains both CM and EM T cells reactive against TA. Upon appropriate activation with DCs, these $\mathrm{T}$ cells, in contrast

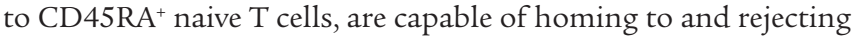
autologous breast cancer transplants in NOD/SCID mice. PSGL1/ P-selectin interactions are suggested to facilitate such homing of memory $\mathrm{T}$ cells to tumors. The eradication of tumor tissues occurs without affecting normal skin transplants. The functional and phenotypic heterogeneity of memory $\mathrm{T}$ cells may be responsible for their complementary functions. EM T cells can efficiently provide an immediate local response on the basis of their reduced activation requirements and increased frequency. In contrast, CM $\mathrm{T}$ cells are capable of rapidly generating a large number of effector cells based on their high proliferative capacity and ability to differentiate into effectors. The generation of two long-term surviving subsets of memory $\mathrm{T}$ cells has recently been visualized in immunized mice (13). We envisage that appropriate in vitro reactivation and expansion of BM derived autologous tumor-specific memory $\mathrm{T}$ lymphocyte populations and their adoptive transfer 
together with TA-pulsed DCs can be applied for effective cellular immunotherapy of cancer patients.

\section{Methods}

Patients. BM samples were obtained from 80 patients with primary breast cancer and from 9 healthy women. Informed consent was obtained from all participants. The protocol was approved by the Ethical Committee of the University of Heidelberg (Heidelberg, Germany). BM samples were aspirated from each anterior iliac crest immediately after surgery while the patients were still anesthetized (48) or 6 months after primary cytostatic treatment using local anesthesia. BM of healthy donors was obtained using local anesthesia. Heparanized BM was subjected to Ficoll gradient centrifugation (Pharmacia, Uppsala, Sweden) and cells in interphase were collected.

Mice. Female NOD/SCID mice (NOD/LtSz-Prkdc scid/J) 6-8 weeks old were purchased from Charles River Wiga GmbH (Sulzfeld, Germany) and were kept in specific pathogen-free conditions. Prior to operations, mice were anesthetized with 1:1:3 (volume/volume/ volume) Rompun (0.1\%; Bayer-Vital, Leverkusen, Germany), Ketanest (0.25\%; Parke-Davis, Berlin, Germany), and PBS.

Tumors. Tissue samples were obtained from breast cancer patients after informed consent was obtained. Freshly excised tumor pieces were transferred immediately into serum-free medium (X-VIVO 20 medium; BioWhittaker, Walkersville, Maryland, USA) and were stored on ice. Tumor biopsies were cut into small cubes with 3- to 5 -mm edges and were implanted subcutaneously into the shaved left flank region within 2-3 hours of the operation. For normal tissue, $5 \times 5-\mathrm{mm}$ skin pieces were obtained during surgery and transplanted subcutaneously into NOD/SCID mice.

Analysis of mice and implanted tumors. The survival and general performance of mice was monitored daily. Tumor size was measured prior to and 4 weeks after adoptive $T$ cell transfer (volume = length $\times$ width $^{2} \times \pi / 6$ ). Tumors were "snap-frozen" in liquid nitrogen for immunohistology.

Flow cytometry. Mononuclear BM cells were treated with human Ig (Endobulin; Immuno, Heidelberg, Germany) and were stained with the following directly conjugated mouse mAb's against human antigens: FITC-CD3 (clone HIT3a), CyChrome-CD4 (clone RPA-T4), CyChrome-CD8 (clone RPA-T8), CyChromeCD45RA (clone HI100), CyChrome-CD62L (clone Dreg 56), and CCR7-biotin (clone 3D12) together with streptavidin-phycoerythrin (streptavidin-PE). All mAb's and streptavidin-PE were from BD Biosciences (San Jose, California, USA). Purified mouse mAb against human PSGL1 (clone KPL1, BD Biosciences) was combined with $\mathrm{PE}$-conjugated goat secondary $\mathrm{mAb}$ against mouse IgG1 (Southern Biotechnology, Birmingham, Alabama, USA). Propidium iodide-negative (PI-negative) viable cells were analyzed by four-color flow cytometry using a FACSCalibur with CELLQuest software (BD Biosciences). FlowJo software (Tree Star, San Carlon, California, USA) was used to analyze 20,000 events. Data were expressed as dot plots or histograms.

Generation of BM-derived T cells and DCs. To obtain T lymphocytes, we incubated BM mononuclear cells for 13 days in RPMI 1640 medium (Gibco-BRL, Eggenstein, Germany) with 10\% human AB serum (PromoCell, Heidelberg, Germany), IL-2 (100 U/ml; Chiron, Ratingen, Germany), and IL-4 (60 U/ml; PromoCell), followed by overnight incubation in the same medium without interleukins (19). Depletion of contaminating B lymphocytes and myeloid precursors was performed with magnetic beads conjugated with
mAb's against CD19 and CD15 (both from Dynal, Oslo, Norway). NK cells were removed using mAb against CD56 (Beckman-Coulter, Krefeld, Germany) and magnetic beads conjugated with mAb against mouse Ig (Dynal). After depletion, the suspension contained $85-95 \%$ CD3 T cells (about 20\% were CD8 T cells). For the generation of DCs, BM mononuclear cells were incubated for to 2 hours on Petri dishes at $37^{\circ} \mathrm{C}$. Adherent cells were further cultured for 7 days in serum-free X-VIVO 20 medium (BioWhittaker) with human GM-CSF (50 ng/ml; Behringwerke, Marburg, Germany) and IL-4 (1,000 U/ml) (19). Nonadherent DCs were enriched by depletion of contaminating $\mathrm{T}$ and $\mathrm{B}$ lymphocytes using magnetic beads conjugated with mAb's against CD3 (Dynal) and CD19 and were pulsed for 20 hours with lysates $\left(200 \mu \mathrm{g}\right.$ protein $/ 10^{6}$ cells/ $\mathrm{ml}$ ) from autologous tumor or normal PBMCs that were lysed by five freeze/thaw cycles (49). In some experiments, DCs were loaded with tumor-specific peptides derived from Her-2/neu (amino acids 369-377; KIFGSLAFL) (35) and MUC1 (LLLLTVLTV) (36) or with irrelevant peptides derived from HIV (gag, amino acids 77-85; SLYNTVATL) (50) and insulin (HLVEALYLV).

IFN- $\gamma$ ELISPOT assay. The number of IFN- $\gamma$-producing T lymphocytes was determined as described previously (19). Briefly, DCs pulsed with the Her-2/neu-derived peptide KIFGSLAFL or the irrelevant, HLA-A2-binding insulin-derived peptide HLVEALYLV were co-incubated with autologous T cells $(\mathrm{DC} / \mathrm{T}$ cell ratio $=1: 5)$ for 40 hours. The number of IFN- $\gamma$ spot-forming cells was measured using an Axioplan 2 microscope and KS ELISPOT software (Carl Zeiss Vision, Hallbergmoos, Germany). Spots measured in the presence of DCs pulsed with the insulin-derived peptide were considered nonspecific background (negative control). Samples were considered to contain tumor-reactive $T$ cells when spot numbers in test triplicates significantly exceeded spot numbers in control triplicates $(P<0.05)$. In these samples, the number of tumor-reactive BM T lymphocytes was calculated as follows: spot numbers in wells with tumor peptide-pulsed DCs minus spot numbers in control wells.

Cytotoxicity assay. The ${ }^{51} \mathrm{Cr}$-release assay was performed as described (19). Briefly, DCs were loaded with peptides (final concentration, $10 \mu \mathrm{g} / \mathrm{ml}$ ) derived from MUC1 (LLLLTVLTV) or HIV (SLYNTVATL). The pulsed DCs were co-incubated for 7 days with autologous $\mathrm{T}$ cells $(\mathrm{DC} / \mathrm{T}$ cell ratio $=1: 5)$ to generate peptide-specific CTLs. ${ }^{51}$ Cr-labeled T2 cells $(174 x C E M$, a TxT hybridoma deficient in transporters of antigen processing TAP1 and TAP2; HLA$\mathrm{A} 2 /-$, B51/-, and $\mathrm{Cw} 01 /-)$ loaded with the peptides mentioned above were used as targets.

$T$ cell staining with HLA-A2/peptide tetramers. Tetrameric complexes containing HLA-A*0201 and Her-2/neu-derived peptide (KIFGSLAFL) or MUC1-derived peptide (LLLLTVLTV) were provided by the National Institute of Allergy and Infectious Diseases (NIAID) Tetramer Facility and NIH AIDS Research and Reference Reagent Program (Bethesda, Maryland, USA). As a control, tetramers containing HLA-A ${ }^{+} 0201$ and HIV-derived peptide (SLYNTVATL) (Immunomics, Paris, France) were used. BM T cells were incubated for 10 minutes on ice with PE-conjugated tetramers, FITC-CD8 (clone HIT8, BD-Bioscience), APC-CD45RA (clone MEM56, Caltag, Burlingame, California, USA), and APCCy7-CD62L (clone DREG-56, Caltag) mAb's followed by fivecolor flow cytometry using a FACSVantage (BD Biosciences). At least $3 \times 10^{5}$ cells were analyzed using FlowJo software (Treestar). Recordings were made only on PI-negative cells, and data were expressed as dot plots. 
Intracellular perforin assay. BM T cells were stimulated with autologous DCs as described for the cytotoxicity assay. Cell permeabilization was performed using a Cytofix/Cytoperm Kit (BD Biosciences). Intracellular perforin production was measured with a perforin staining kit (BD Biosciences). In addition, cells were stained with mAb's against CD8, CD45RA and CCR7 followed by flow cytometry as described above.

$A D I$. DCs were pulsed with the lysates from autologous tumors or PBMCs followed by co-incubation with autologous BM-derived cultured T cells $(\mathrm{DC} / \mathrm{T}$ cell ratio $=1: 5)$ for 20 hours. Then, $5 \times 10^{6}$ $\mathrm{T}$ cells and $1 \times 10^{6}$ DCs were injected intraperitoneally into NOD/SCID mice 16 days after tumor implantation. In most experiments, cultured $\mathrm{T}$ cells were sorted for CD45RA ${ }^{+}$naive and $\mathrm{CD}^{2}$ RA- $\mathrm{CD}^{-}$450 ${ }^{+}$memory cells using MACS colloidal superparamagnetic MicroBeads conjugated with mouse $\mathrm{mAb}$ against human CD45RA (Miltenyi Biotec, Bergisch Gladbach, Germany). The sorted CD45RA ${ }^{+}$and CD45RA- T cells were each re-stimulated with pulsed DCs and inoculated intraperitoneally into mice 16 days after tumor implantation. Each animal received $2.5 \times 10^{6}$ memory or $2.5 \times 10^{6}$ naive T cells plus $0.5 \times 10^{6} \mathrm{DCs}$.

Immunohistochemistry. Consecutive cryostat sections $5 \mu \mathrm{m}$ in thickness were fixed for 10 minutes in acetone supplemented with $3 \% \mathrm{H}_{2} \mathrm{O}_{2}$ to block endogenous peroxidase, air-dried, and stained with mouse mAb's against human antigens: CD3 (clone T3-4B5; DAKO, Hamburg, Germany), CD4 (clone MT310; DAKO), CD8 (clone DK25; DAKO), CD45RO (clone UCHL1; DAKO), CD45RA (clone 4KB5, DAKO), CD11c (clone KB90; DAKO), P-selectin (clone 1E3; DAKO), PSGL-1 (clone KPL1; BD Biosciences), CD62L (clone FMC46; DAKO), CD25 (clone ACT1; DAKO), CD26 (clone BA5; DAKO), or CD69 (clone FN50; DAKO). Staining was performed using an immunostainer (Mirastainer; Merck, Darmstadt, Germany). For double staining, alkaline phosphatase-coupled secondary Ab (clone K4017, DAKO) was additionally used. As a substrate, 3-amino-9-ethylcarbazole (AEC Chromogen; Merck) or BCIP-NBT (K598; DAKO) was used for peroxidase (red color) or alkaline phosphatase (dark blue color), respectively. Apoptotic cells were detected by the TUNEL method (Roche, Mannheim, Germany). For detection of perforin, slides were incubated for 1 minute in $0.1 \%$ Triton $\mathrm{X}-100$ (Merck) prior to incubation with mouse $\mathrm{mAb}$ against human perforin (clone 58-020; Ancell, North Bayport, Minnesota, USA). Some sections were counterstained with hemalaun (Merck).

\section{Acknowledgments}

We thank L. Bai for help with cell cultures, B. Kyewski for comments on the manuscript, G. Moldenhauer for human Ig, A. Benner for help with statistics, and J. Foerster and M. Gehring for excellent technical assistance. We thank the NIAID Tetramer Facility and NIH AIDS Research and Reference Reagent Program (Bethesda, Maryland, USA) for providing HLA-A2 peptide tetrameric complexes, and the M. Scheel-Stiftung (grant 10-1589-Schi5) and the Tumorzentrum Heidelberg/Mannheim (grant Tumorzentrum FSP III./8.) for financial support.

Received for publication October 13, 2003, and accepted in revised form May 4, 2004.

Address correspondence to: Viktor Umansky, Clinical Cooperation Unit Dermato-Oncology, German Cancer Research Center, Im Neuenheimer Feld 280, 69120 Heidelberg, Germany. Phone: 49-621-383-3773; Fax: 49-621-383-2163; E-mail:v.umansky@dkfzheidelberg.de.

M. Feuerer's present address is: Division of Experimental Rheumatology, Charité, Humboldt University, Berlin, Germany.

V. Umansky's present address is: Clinical Cooperation Unit DermatoOncology, German Cancer Research Center, Heidelberg, Germany.
1. Zinkernagel, R.M., et al. 1996. On immunological memory. Annu. Rev. Immunol. 14:333-367.

2. Goldrath, A.W., and Bevan, M.J. 1999. Selecting and maintaining a diverse T-cell repertoire. Nature. 402:255-262.

3. Westermann, J., et al. 2001. Migration of naive, effector and memory T cells: implications for the regulation of immune responses. Immunol. Rev. 184:20-37.

4. Veiga-Fernandes, H., Walter, U., Bourgeois, C., McLean, A., and Rocha, B. 2000. Response of naive and memory $\mathrm{CD}^{+} \mathrm{T}$ cells to antigen stimulation in vivo. Nat. Immunol. 1:47-53.

5. Tuma, R.A., and Palmer, E.G. 2002. Homeostasis of naive, effector and memory CD8 T cells. Curr. Opin. Immunol. 14:348-353.

6. Lanzaveccia, A., and Sallusto, F. 2000. From synapses to immunological memory: the role of sustained T cell stimulation. Curr. Opin. Immunol. 12:92-98.

7. Michie, C.A., McLean, A., Alcock, C., and Beverley, P.C. 1992. Lifespan of human lymphocyte subsets defined by CD45 isoforms. Nature. 360:264-265.

8. Butcher, E.C., Williams, M., Youngman, K., Rott, L., and Briskin, M. 1999. Lymphocyte trafficking and regional immunity. Adv. Immunol. 72:209-253.

9. Forster, R., et al. 1999. CCR7 coordinates the primary immune response by establishing functional microenvironments in secondary lymphoid organs. Cell. 99:23-33.

10. Xie, H., Lim, Y.C., Luscinskas, F.W., and Lichtman, A.H. 1999. Acquisition of selectin binding and peripheral homing properties by $\mathrm{CD}^{+}$and $\mathrm{CD}^{+}$
T cells. J. Exp. Med. 189:1765-1776.

11. Sallusto, F., Lenig, D., Forster, R., Lipp, M., and Lanzavecchia, A. 1999. Two subsets of memory T lymphocytes with distinct homing potentials and effector functions. Nature. 401:708-712.

12. Masopust, D., Vecys, V., Marzo, A.L., and Lefrancois, L. 2001. Preferential localization of effector memory cells in nonlymphoid tissue. Science. 291:2413-2417.

13. Reinhardt, R.L., Khoruts, A., Merica, R., Zell, T., and Jenkins, M.K. 2001. Visualizing the generation of memory CD4 T cells in the whole body. Nature. 410:101-105.

14. Manjunath, N., et al. 2001. Effector differentiation is not prerequisite for generation of memory cytotoxic T lymphocytes. J. Clin. Invest. 108:871-878. doi:10.1172/JCI200113296.

15. Tough, D.F. 2003. Deciphering the relationship between central and effector memory $\mathrm{CD}^{+} \mathrm{T}$ cells. Trends Immunol. 24:404-407.

16. Khazaie, K., et al. 1994. Persistence of dormant tumor cells in the bone marrow of tumor cellvaccinated mice correlates with long-term immunological protection. Proc. Natl. Acad. Sci. U. S. A. 91:7430-7434.

17. Muller, M., et al. 1998. EblacZ tumor dormancy in bone marrow and lymph nodes: active control of proliferating tumor cells by $\mathrm{CD}^{+}{ }^{+}$immune $\mathrm{T}$ cells. Cancer Res. 58:5439-5446.

18. Feuerer, M., et al. 2001. Enrichment of memory T cells and other profound immunological changes in the bone marrow from untreated breast cancer patients. Int. J. Cancer. 92:96-105.
19. Feuerer, M., et al. 2001. Therapy of human tumors in NOD/SCID mice with patient derived re-activated memory T cells from bone marrow. Nat. Med. 7:452-458.

20. Rivoltini, L., et al. 2002. Immunity to cancer: attack and escape in Tlymphocyte-tumor cell interaction. Immunol. Rev. 188:97-113.

21. Yee, C., et al. 2000. Melanocyte destruction after antigen-specific immunotherapy of melanoma: direct evidence of T cell-mediated vitiligo. J. Exp. Med. 192:1637-1643.

22. Dudley, M.E., et al. 2002. Cancer regression and autoimmunity in patients after clonal repopulation with antitumor lymphocytes. Science. 298:850-854.

23. Geijtenbeek, B., et al. 2000. Identification of DCSIGN, a novel dendritic cell-specific ICAM-3 receptor that supports primary immune responses. Cell. 100:575-585.

24. Lim, Y.C., et al. 1999. Expression of functional selectin ligands on Th cells is differentially regulated by IL-12 and IL-4. J. Immunol. 15:3193-3201.

25. Lim, Y.C., et al. 2001. IL-12, STAT4-dependent up-regulation of $\mathrm{CD}^{+} \mathrm{T}$ cell core 2 beta-1,6-nacetylglucosaminyltransferase, an enzyme essential for biosynthesis of P-selectin ligands. J. Immunol. 167:4476-4484.

26. Marshall, D.R., et al. 2001. Measuring the diaspora for virus-specific CD8 ${ }^{+}$T cells. Proc. Natl. Acad. Sci. U. S. A. 98:6313-6318.

27. Greiner, D.L., et al. 1995. Improved engraftment of human spleen cells in NOD/LtSz-scid/scid mice as compared with C.B-17-scid/scid mice. Am. J. Pathol. 146:888-902. 


\section{research article}

28. Visonneau, S., Cesano, A., Torosian, M.H., Miller, E.J., and Santoli, D. 1998. Growth characteristics and metastatic properties of human breast cancer xenografts in immunodeficient mice. Am. J. Pathol. 152:1299-1311.

29. Beckhove, P., et al. 2003. Efficient engraftment of human primary breast cancer transplants in NOD/ SCID mice. Int. J. Cancer. 105:444-453.

30. Bai, L., et al. 2003. Cognate interactions between memory $\mathrm{T}$ cells and tumor antigen-presenting dendritic cells from bone marrow of breast cancer patients: Bidirectional cell stimulation, survival and antitumor activity in vivo. Int. J. Cancer. 103:10-20.

31. Schirrmacher, V., Schild, H.J., Gückel, B., and von Hoegen, P. 1992. Tumor specific CTL response requiring interactions of four different cell types and dual recognition of MHC class I and class II restricted tumor antigens. Immunol. Cell Biol. 71:311-326.

32. Hung, K., et al. 1998. The central role of $\mathrm{CD}^{+} \mathrm{T}$ cells in the antitumor immune response. J. Exp. Med. 188:2357-2368.

33. Bankert, R.B., Egilmez, N.K., and Hess, S.D. 2001. Human-SCID mouse chimeric models for the evaluation of anti-cancer therapies. Trends Immunol. 22:386-393.

34. Tary-Lehmann, M., and Saxon, A. 1992. Human mature $\mathrm{T}$ cells that are anergic in vivo prevail in SCID mice reconstituted with human peripheral blood. J. Exp. Med. 175:503-516.

35. Fisk, B., Blevins, T.L., Wharton, J.T., and Ioannides, C.G. 1995. Identification of an immunodominant peptide of HER-2/neu protooncogene recognized by ovarian tumor-specific cytotoxic T lymphocyte lines. J. Exp. Med. 181:2109-2117.

36. Brossart, P., et al. 1999. Identification of HLA-A2restricted T-cell epitopes derived from the MUC1 tumor antigen for broadly applicable vaccine therapies. Blood. 93:4309-4317.

37. Valmori, D., et al. 2002. Circulating tumor-reactive $\mathrm{CD}^{+} \mathrm{T}$ cells in melanoma patients contain a CD45RA ${ }^{+} \mathrm{CCR}^{-}$effector subset exerting ex vivo tumor-specific cytolytic activity. Cancer Res. 62:1743-1750

38. Trapani, J.A., and Smyth, M.J. 2002. Functional significance of the perforin/granzyme cell death pathway. Nat. Rev. Immunol. 2:735-747.

39. Reinhardt, R., Bullard, D., Weaver, C., and Jenkins, M. 2003. Preferential accumulation of antigen-specific effector CD4 $\mathrm{T}$ cells at an antigen injection site involves CD62E-dependent migration but not local proliferation. J. Exp. Med. 197:751-762.

40. Wherry, E., et al. 2003. Lineage relationship and protective immunity of memory CD8 $\mathrm{T}$ cell subsets. Nat. Immunol. 4:225-234.

41. Fox, S.B., Turner, G.D., Gatter, K.C., and Harris, A.L. 1995. The increased expression of adhesion molecules ICAM-3, E- and P-selectins on breast cancer endothelium. J. Pathol. 177:369-376.

42. Iezzi, G., Karjalainen, K., and Lanzavecchia, A. 1998. The duration of antigenic stimulation determines the fate of naive and effector T cells. Immunity. 8:89-95.

43. Bai, L., Koopmann, J., Fiola, C., Fournier, P., and Schirrmacher, V. 2002. Dendritic cells pulsed with viral oncolysates potently stimulate autologous T cells from cancer patients. Int. J. Oncol. 21:685-694. 44. Gillespie, K.M., Szeto, C.C., Betin, V.M., and Mathieson, P.W. 2000. Role of beta1 and beta2 subunits of the interleukin-12 receptor in determining $\mathrm{T}$ helper $1 / \mathrm{T}$ helper 2 responses in vivo in the rat. Immunology. 99:109-112.

45. Zhang, X., Sun, S., Hwang, I., Tough, D.F., and Sprent, J. 1998. Potent and selective stimulation of memory-phenotype CD8 ${ }^{+} \mathrm{T}$ cells in vivo by interleukin-15. Immunity. 8:591-599.

46. Geginat, J., Sallusto, F., and Lanzavecchia, A. 2001. Cytokine-driven proliferation and differentiation of human naive, central memory, and effector memory CD4 ${ }^{+}$T cells. J. Exp. Med. 194:1711-1719.

47. Wong, B.R., et al. 1997. TRANCE (tumor necrosis factor [TNF]-related activation-induced cytokine), a new TNF family member predominantly expressed in T cells, is a dendritic cell-specific survival factor. J. Exp. Med. 186:2075-2080.

48. Diel, I.J., et al. 1996. Micrometastatic breast cancer cells in bone marrow at primary surgery: prognostic value in comparison with nodal status. J. Natl. Cancer Inst. 88:1652-1658.

49. Sauter, B., et al. 2000. Consequences of cell death: exposure to necrotic tumor cells, but not primary tissue cells or apoptotic cells, induces the maturation of immunostimulatory dendritic cells. J. Exp. Med. 191:423-434.

50. Tsomides, T.J., et al. 1994. Naturally processed viral peptides recognized by cytotoxic T lymphocytes on cells chronically infected by human immunodeficiency virus type 1. J. Exp. Med. 180:1283-1293. 